NASA-TM-106,566

\title{
Theoretical and Experimental Study of Microstrip-to-Slot Line Uniplanar Transition
}

Jong-Gwan Yook, Nihad I. Dib, and Linda P.B. Katehi

The University of Michigan

Ann Arbor, Michigan

Rainee N. Simons

NYMA, Inc.

2001 Aerospace Parkway

Brook Park, Ohio

and

Susan R. Taub

National Aeronautics and Space Administration

Lewis Research Center

Cleveland, Ohio

Prepared for the

1994 IEEE AP-S International Symposium and URSI Radio Science Meeting sponsored by the Institute of Electrical and Electronics Engineers Seattle, Washington, June, 19-24, 1994
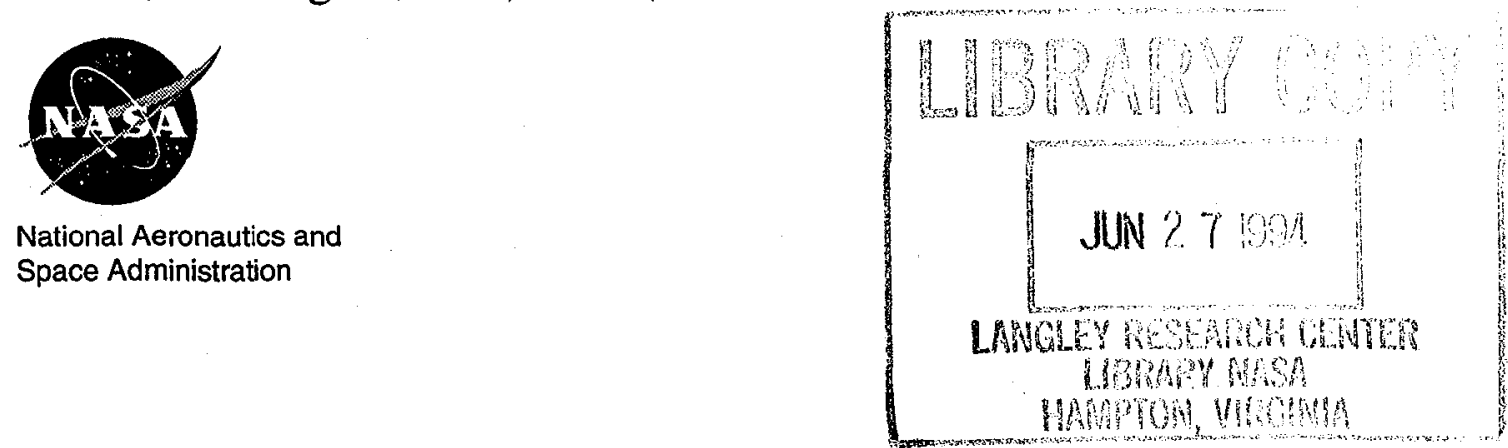


\title{
Theoretical and Experimental Study of Microstrip-to-Slot Line Uniplanar Transition
}

\author{
Jong-Gwan Yook ${ }^{*}$, Nihad I. Dib, and Linda P.B. Katehi \\ The University of Michigan \\ Ann Arbor, MI 48109 \\ Rainee N. Simons \\ NYMA, Inc. \\ 2001 Aerospace Parkway \\ Brook Park, Ohio 44142 \\ and \\ Susan R. Taub \\ National Aeronautics and Space Administration \\ Lewis Research Center \\ Cleveland, Ohio 44135
}

\begin{abstract}
Summary
Recent advances in MMIC technology makes it possible to construct transitions from CPW-to-microstrip with via hole, microstrip-to-slot line and microshield line-to-CPW all of which have potential applications in the feed network of antennas. In this study we investigate the characteristics of the microstrip-to-slot line uniplanar transition using the finite element method (FEM) and finite difference time domain (FDTD) technique, and compared the theoretical results with the measurements. In both cases, the results agree with the measurements within a few percent.
\end{abstract}

\section{Introduction}

Many of planar microwave circuit discontinuities have been characterized accurately with full wave integral equation (IE) techniques [1,2]. However, these approaches are limited to simple geometries. Frequency and time domain volume discretization techniques are more appropriate for the treatment of complex geometries involving arbitrary shapes. In this paper, the finite element method and the finite difference time domain technique have been employed for the characterization of the microstrip-to-slotline transition shown in Figure 1. This type of transition has potential to integrate MMIC based components such as phase shifters and amplifiers in the feed network of linearly tapered slot antenna arrays [3]. Derived theoretical data are compared to measurements. A brief summary of both techniques and explanations of the results will be given below. 


\section{Formulations}

\section{A. FINITE ELEMENT METHOD}

To apply the finite element technique we subdivide the considered space into tetrahedrons which are suitable for an arbitrary geometry. With this tetrahedral element the edge-based vector basis function [4] is employed to represent the local electromagnetic fields. For a given tetrahedron there are 6 edges and accordingly it has 6 unknowns per element. After we represent the field in a tetrahedron as a linear combination of six edge basis function, the energy functional derived from Maxwell's equations using Galerkin's procedure is minimized with respect to unknown coefficients. As a result we have a linear system of equations and the resulting FEM matrix is highly sparse and symmetric. This matrix equation is solved by using the preconditioned bi-conjugate gradient method with only non-zero matrix entries. Moreover, since there is a geometrical symmetry we can reduce the size of the problem to half of the original one.

For the electric field formulation with ideal current excitation, the geometrical symmetry can be taken into account by incorporating a perfect magnetic (pmc) or electric (pec) wall depending upon even or odd excitations. If a geometry has longitudinal symmetry on which the tangential magnetic field is zero, we can consider that plane as a pmc wall regardless of excitations. Following the solution of the problem for each one of the excitation, the scattering parameters are evaluated using standard network techniques.

\section{B. FINITE DIFFERENCE TIME DOMAIN TECHNIQUE}

In order to characterize any planar discontinuity using the FDTD technique, Maxwwell's curl equations are expressed in discretized space and time domains. As an excitation, a Gaussian pulse is used because it varies smoothly in time and its Fourier transform is also a Gaussian function centered at zero frequency. Following the time and space discretizations of the electric and magnetic field components, the FDTD equivalents of Maxwell's equations are then used to update the spatial distributions of these components at alternating half time steps. The space steps, $\Delta x, \Delta y$, and $\Delta z$, are carefully chosen such that integral numbers of them can approximate the various dimensions of the structure. After the pulse has been launched, the ground plane at the front wall is switched into an absorbing boundary. The super-absorbing first-order Mur boundary condition is utilized to terminate the FDTD lattice at the front and back walls in order to simulate infinite lines and the first-order Mur boundary condition at the top and side walls.

In general, the frequency dependent scattering parameters, $S_{i j}$, can be obtained from the voltages at ports $i$ and $j$. To obtain $S_{11}(\omega)$, the incident and reflected fields must be known. The incident field is obtained from that of an infinite extent line (i.e., from the source to far absorbing wall). Then, this incident field is subtracted from the total waveform to yield the reflected field.

\section{Results and Discussion}

Figure 1 shows the schematic diagram of the microstrip-to-slot line uniplanar transition. The two side arms of the microstrip $\mathrm{T}$-junction are bent to form a circle. The circular microstrip 
lengths a-b-c and a-d differ by $\lambda_{g(m i c r o s t r i p)} / 2$ at a design frequency of $10 \mathrm{GHz}$, thus making the fields at the locations $c$ and $d 180^{\circ}$ out of phase. This is necessary to excite the odd mode on the coupled microstrip lines. The characteristic impedances of the various lines are also indicated in Figure 1. The transition was fabricated on a $0.635 \mathrm{~mm}$ thick RT-Duroid 1010.5 with dielectric constant $\varepsilon_{\mathrm{T}}$ equal to 10.5 .

Figure 2 shows measurements vs. theory for the transition in an open and shielded environment. Specifically, the measurements where performed in the open transition while the theory considered a completely shielded environment. This difference is mainly responsible for the $3 \%$ change in the resonant frequency. Furthermore the measurements included conductor, dielectric, and radiation loss, while the theory considered a lossless case. As a result, the experimental data have a much broader resonance than the theoretical one. Figure 3 shows data derived through the FDTD method for the open transition shown in the same figure and verifies the claim made above. Specifically, there is a clear reduction in the resonant frequency from the shielded case and there is a considerable amount of radiation loss as shown in Figure 4. Using the above techniques, a parametric study of these transitions will be performed and the efficiencies of the two techniques in terms of computational times and accuracy will be discussed.

\section{Conclusion}

In this study, the characteristics of the transition of microstrip-to-slot line which can be used as a feeding network of the tapered slot antenna are examined and the theoretical and experimental results are compared. This transition has very narrow bandwidth characteristics inherently. When there is considerable amount of radiation from the circuit, the numerical computations which is performed under shielding condition does not predict exactly the characteristics of the circuit.

\section{References}

[1] Linda P.B. Katehi, "Novel Transmission Lines for the Submillimeter-Wave Region," Proceedings of the IEEE, vol. 80, No. 11, pp. 1771-1787, Nov. 1992.

[2] N.L. VandenBerg and Linda P.B. Katehi, "Generalized Full-Wave Treatment of Shielded Multilayer Structures Using the Vector Wave Function Field Expansion Method," Electromagnetics, vol. 13, pp. 67-84, 1993.

[3] R.N. Simons, T.D. Perl, and R.O. Lee, "New Coplanar Waveguide Feed Network for $2 \times 2$ Linearly Tapered Slot Antenna Subarray," Microwave and Optical Technology Letters, vol. 5, No. 9, pp. 420-423, Aug. 1992.

[4] M.L. Barton and Z.J. Cendes, "New Vector Finite Elements for Three-Dimensional Magnetic Field Computation," J. Appl. Phys., vol. 61, No. 8, pp. 3919-3921, Apr. 1987. 


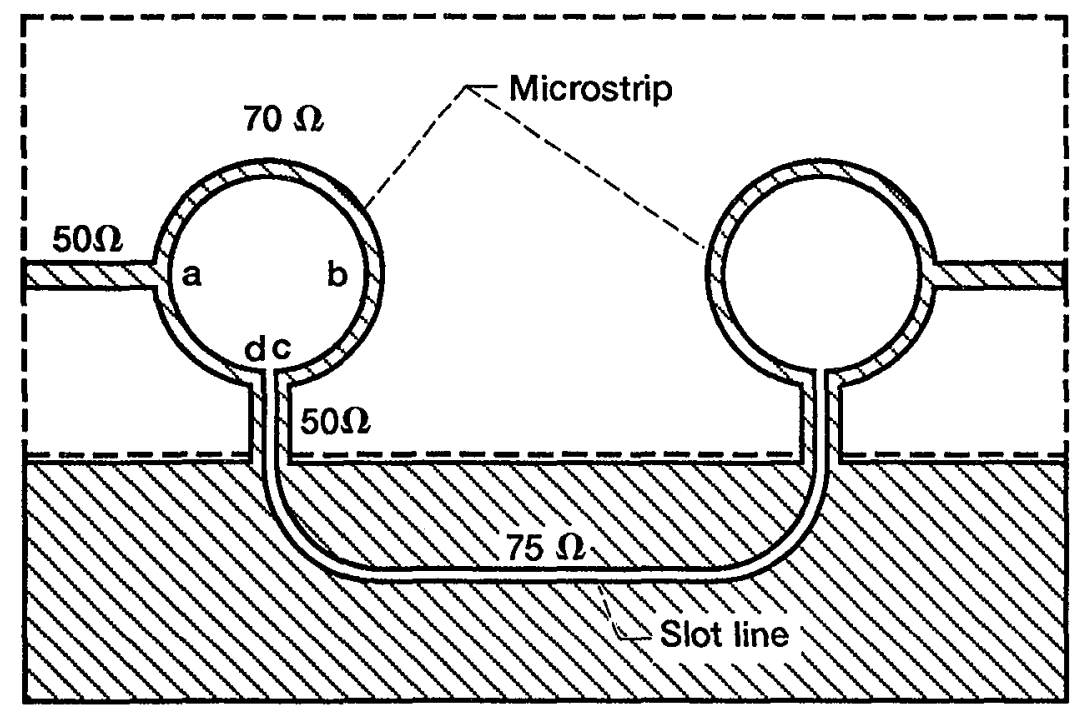

Figure 1.-Schematic diagram of microstript-to-slot line uniplanar transition.

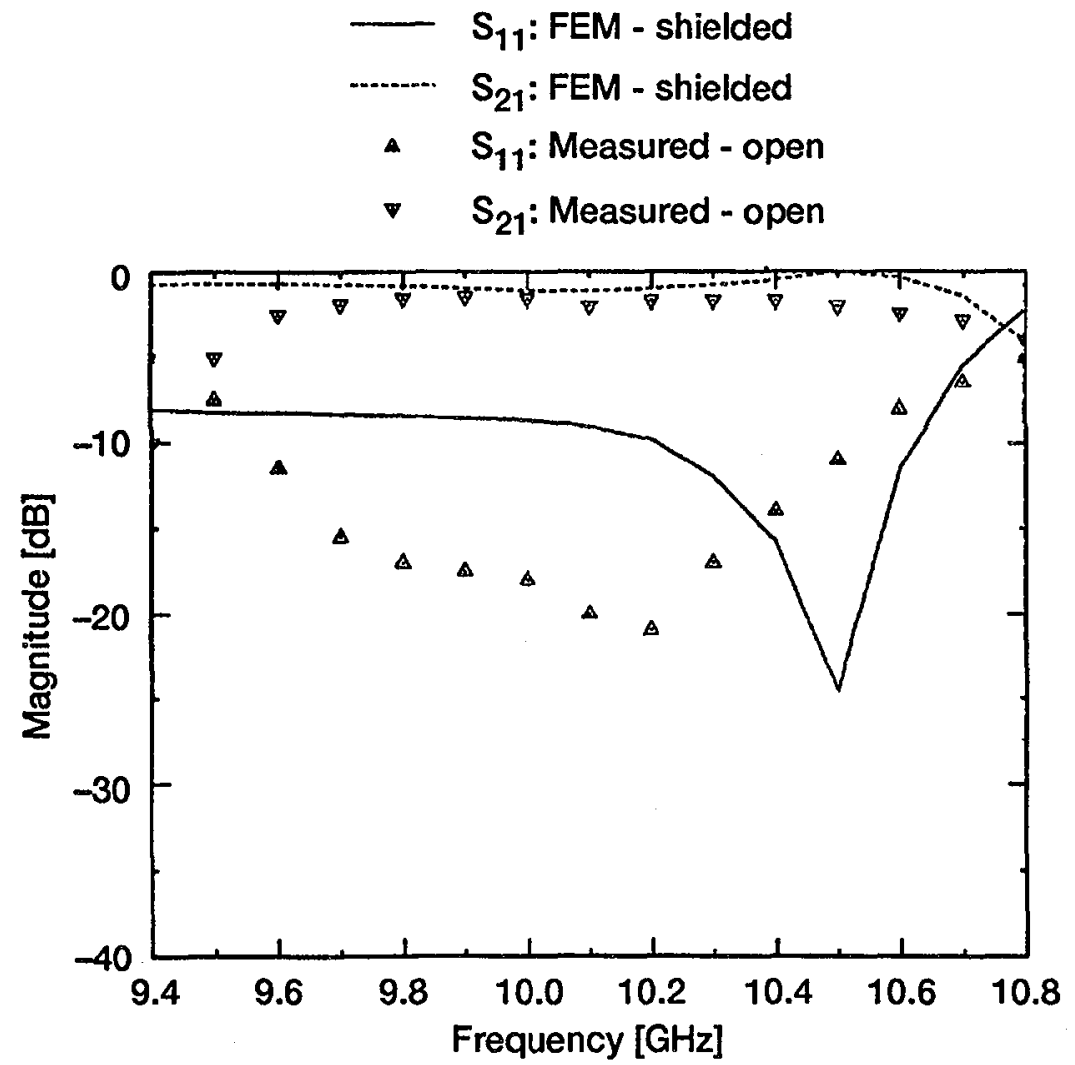

Figure 2.-Scattering parameters for the microstrip-to-slot line transition. Comparison between FEM results and measurement. 


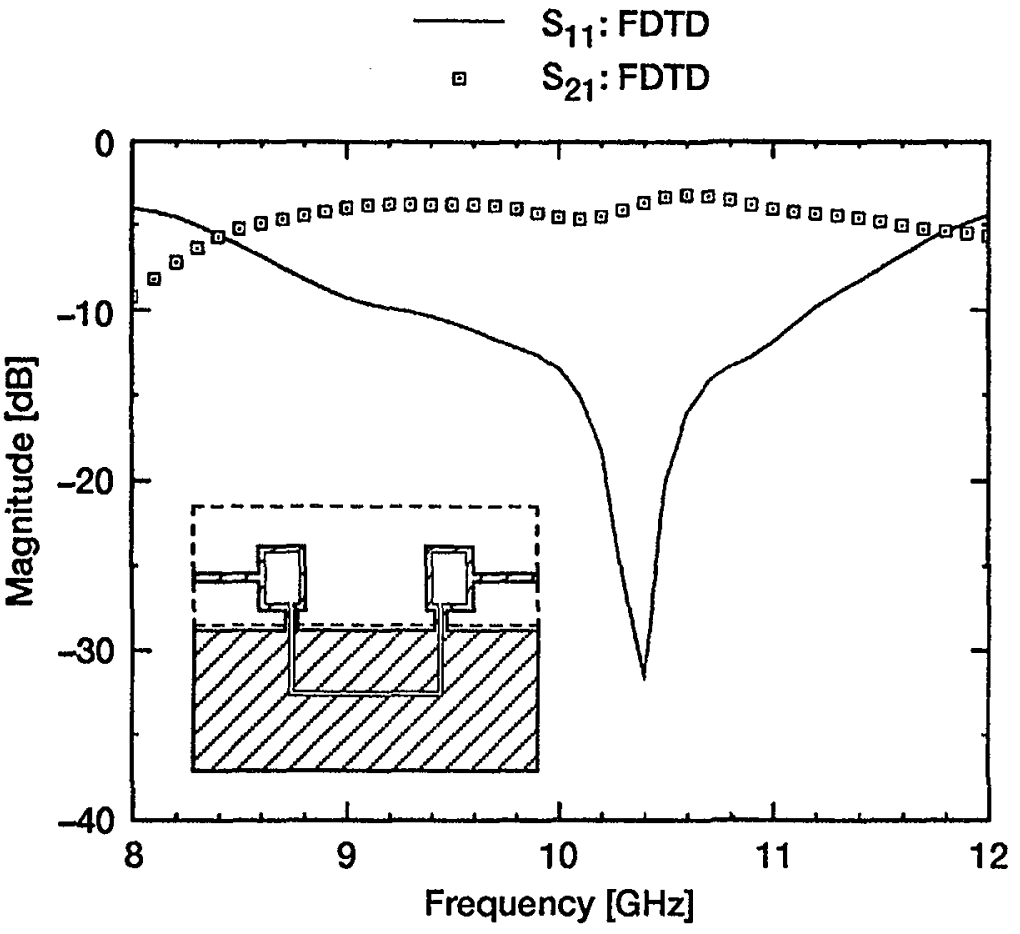

Figure 3.-Scattering parameters computed by FDTD method with rectangular loop for the microstrip-to-slot line transition.

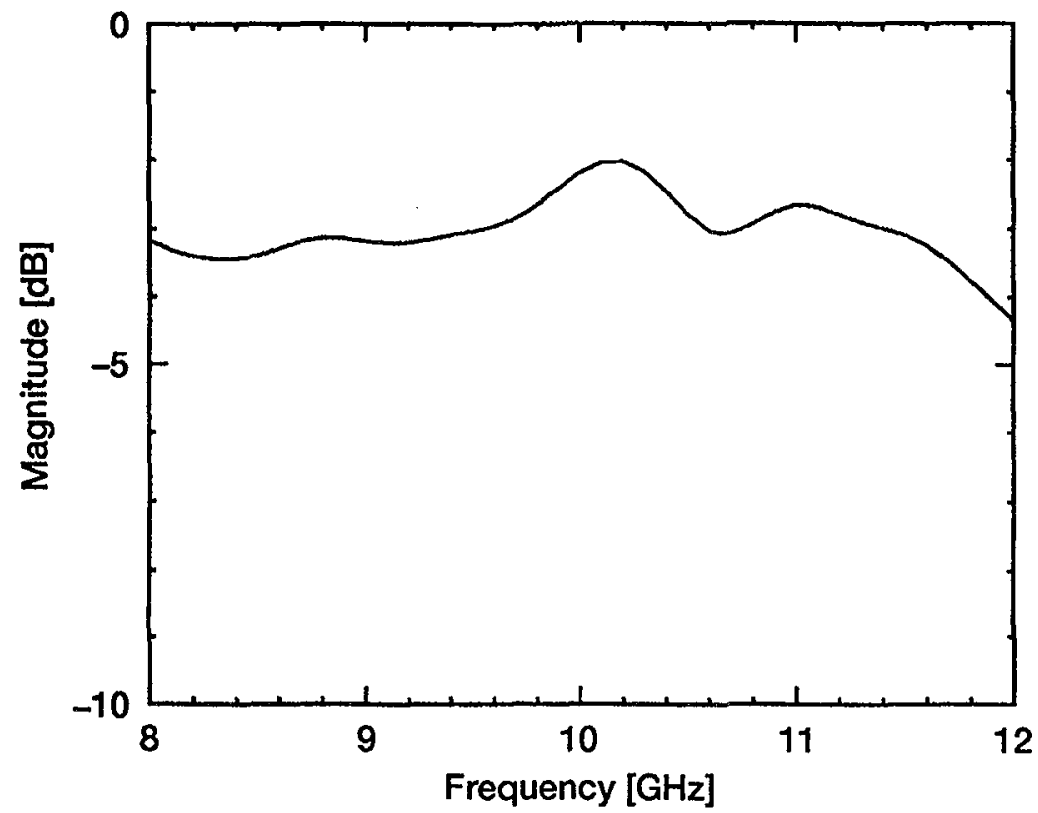

Figure 4.-Radiation loss of the microstrip-to-slot line transition obtained from the FDTD results. 
Public reporting burden for this collection of information is estimated to average 1 hour per response, including the time for reviewing instructions, searching existing data sources, gathering and maintaining the data needed, and completing and reviewing the collection of information. Send comments regarding this burden estimate or any other aspect of this collection of information, including suggestions for reducing this burcen, to Washington Headquarters Services, Directorate for Information Operations and Reports, 1215 Jefferson Davis Highway, Suite 1204, Arlington. VA 22202-4302, and to the Office of Management and Budget, Paperwork Reduction Project (0704-0188), Washington, DC 20503.
1. AGENCY USE ONLY (Leave blank)
2. REPORT DATE
May 1994
3. REPORT TYPE AND DATES COVERED
Technical Memorandum

4. TITLE AND SUBTITLE

5. FUNDING NUMBERS

Theoretical and Experimental Study of Microstrip-to-Slot Line

Uniplanar Transition

6. AUTHOR(S)

Jong-Gwan Yook, Nihad I. Dib, Linda P.B. Katehi,

Rainee N. Simons, and Susan R. Taub

WU-506-44-2C

7. PERForming ORGANIZATION NAME(S) AND ADDRESS(ES)

National Aeronautics and Space Administration

Lewis Research Center

Cleveland, Ohio 44135-3191

8. PERFORMING ORGANIZATION REPORT NUMBER

$\mathrm{E}-8743$

9. SPONSORING/MONITORING AGENCY NAME(S) AND ADDRESS(ES)

10. SPONSORING/MONITORING AGENCY REPORT NUMBER

National Aeronautics and Space Administration

Washington, D.C. 20546-0001

NASA TM-106566

\section{SUPPLEMENTARY NOTES}

Prepared for the 1994 IEEE AP-S International Symposium and URSI Radio Science Meeting sponsored by the Institute of Electrical and Electronics Engineers, Seattle, Washington, June 19-24, 1994. Jong-Gwan Yook, Nihad I. Dib, and Linda P.B. Katehi, The University of Michigan, Ann Arbor, Michigan 48109; Rainee N. Simons, NYMA, Inc., 2001 Aerospace Parkway, Brook Park, Ohio 44142 (work funded by NASA Contract NAS3-27186);

Susan R. Taub, NASA Lewis Research Center. Responsible person, Rainee N. Simons, organization code 5630, (216) 433-3462.

12a. DISTRIBUTION/AVAILABILITY STATEMENT

12b. DISTRIBUTION CODE

Unclassified - Unlimited

Subject Category 33

13. ABSTRACT (Maximum 200 words)

Recent advances in MMIC technology makes it possible to construct transitions from CPW-to-microstrip with via hole, microstrip-to-slot line and microshield line-to-CPW all of which have potential applications in the feed network of antennas. In this study we investigate the characteristics of the microstrip-to-slot line uniplanar transition using the finite element method (FEM) and finite difference time domain (FDTD) technique, and compared the theoretical results with the measurements. In both cases, the results agree with the measurements within a few percent.

\begin{tabular}{|l|l|l|}
\hline 14. SUBJECT TERMS \\
Microstrip-to-slot line; Uniplanar transition \\
$\begin{array}{c}\text { 17. SECURITY CLASSIFICATION } \\
\text { OF REPORT } \\
\text { Unclassified }\end{array}$ & $\begin{array}{c}\text { 18. SECURITY CLASSIFICATION } \\
\text { OF THIS PAGE } \\
\text { Unclassified }\end{array}$ & $\begin{array}{c}\text { 19. SECURITY CLASSIFICATION } \\
\text { OF ABSTRACT } \\
\text { Unclassified }\end{array}$ \\
\hline
\end{tabular}

